\title{
Forms of nitrogen uptake, translocation, and transfer via arbuscular mycorrhizal fungi: A review
}

\author{
JIN HaiRu*, LIU Jie, LIU Jing \& HUANG XiaoWei \\ College of Chemistry and Life Science, Zhejiang Normal University, Jinhua 321004, China
}

Received February 17, 2012; accepted April 6, 2012

\begin{abstract}
Arbuscular mycorrhizal (AM) fungi are obligate symbionts that colonize the roots of more than $80 \%$ of land plants. Experiments on the relationship between the host plant and AM in soil or in sterile root-organ culture have provided clear evidence that the extraradical mycelia of AM fungi uptake various forms of nitrogen $(\mathrm{N})$ and transport the assimilated $\mathrm{N}$ to the roots of the host plant. However, the uptake mechanisms of various forms of $\mathrm{N}$ and its translocation and transfer from the fungus to the host are virtually unknown. Therefore, there is a dearth of integrated models describing the movement of $\mathrm{N}$ through the AM fungal hyphae. Recent studies examined Ri T-DNA-transformed carrot roots colonized with AM fungi in ${ }^{15} \mathrm{~N}$ tracer experiments. In these experiments, the activities of key enzymes were determined, and expressions of genes related to $\mathrm{N}$ assimilation and translocation pathways were quantified. This review summarizes and discusses the results of recent research on the forms of $\mathrm{N}$ uptake, transport, degradation, and transfer to the roots of the host plant and the underlying mechanisms, as well as research on the forms of $\mathrm{N}$ and carbon used by germinating spores and their effects on amino acid metabolism. Finally, a pathway model summarizing the entire mechanism of $\mathrm{N}$ metabolism in AM fungi is outlined.
\end{abstract}

arbuscular mycorrhizae, arginine, nitrogen metabolism, nitrogen translocation, symbiosis

Citation: Jin H R, Liu J, Liu J, et al. Forms of nitrogen uptake, translocation, and transfer via arbuscular mycorrhizal fungi: A review. Sci China Life Sci, 2012, 55: 474-482, doi: 10.1007/s11427-012-4330-y

Arbuscular mycorrhizal (AM) fungi are obligate symbionts that colonize the roots of more than $80 \%$ of terrestrial plants. They provide a variety of benefits to their hosts, including increased nutrient uptake under low-input conditions [1], resistance to plant pests, improved water relations and drought resistance, and increased growth and yield. The extraradical mycelium (ERM) of the fungus acts as an extension of the root system, which enables a more thorough exploration of the soil for nutrients that are then transported to the roots. Although the benefits of AM fungi are more common for nutrients that are immobile in the soil solution, such as phosphorus (P) and zinc [2,3], AM fungi can also enhance the nitrogen $(\mathrm{N})$ nutrition of their hosts [4-6]. The extraradical AM fungal hyphae effectively acquire nitrate

*Corresponding author (email: hrjin@zjnu.cn)
$\left(\mathrm{NO}_{3}{ }^{-}\right)$[7,8], ammonium $\left(\mathrm{NH}_{4}^{+}\right)$[9-12], and amino acids (AAs) from the external medium [13-16].

However, because of a lack of standardized methodologies, the difficulty in separating plant and fungal responses, and the complex metabolic interactions between $\mathrm{N}$ and other nutrients, there is contradicting evidence about fungal $\mathrm{N}$ metabolism, and little is known about the uptake mechanisms of various forms of $\mathrm{N}$ [17]. Furthermore, the mechanisms of translocation and transfer of some nutrients from the fungus to the host are virtually unknown. The availability and mobility of $\mathrm{N}$ is important to the plant; thus, its uptake and transport mechanisms are of considerable interest [9]. Despite that, there is a dearth of integrated models describing the movement of $\mathrm{N}$ through the AM fungal hyphae, a situation that contradicts the well-developed flow 
mechanism for $\mathrm{P}$ [18] and the emerging models for carbon (C) flow $[19,20]$.

In terms of the mechanism for $\mathrm{N}$ transfer, Smith et al. [21] suggested that AA or amides may be the compounds transferred from the fungus to the host. Along these lines, Kaldorf et al. [22] suggested that $\mathrm{NO}_{3}^{-}$may be transferred. Bago et al. [23] postulated that $\mathrm{N}$ may be transferred to the host as $\mathrm{NH}_{4}{ }^{+}$; however, there was no direct evidence for this, and the indirect evidence was at best inconclusive. Recently, several studies have made progress on $\mathrm{N}$ uptake, translocation, and transfer via AM fungi through ${ }^{15} \mathrm{~N}$ isotopic labeling, measurements of key enzymes, and analyses of expressions of related genes [24-29]. The form of $\mathrm{N}$ transport along the mycelium and its metabolic pathways in the AM fungus Glomus intraradices have been well documented. More recently, it was found that $\mathrm{N}$ uptake and transport in $\mathrm{AM}$ symbiosis are triggered by $\mathrm{C}$ flux from the mycorrhizal host plant to the fungus [30], and that this increase is orchestrated by changes in fungal gene expression, a similar reward mechanism to that described for $\mathrm{P}$ and $\mathrm{C}$ exchange [31]. In contrast, Olsson et al. [32] reported that the allocation of $\mathrm{C}$ to the $\mathrm{AM}$ fungi depended on the $\mathrm{N}$ sta- tus of the mycorrhizal root, indicating that the stoichiometry of $\mathrm{C}$ and $\mathrm{N}$ regulates the nutrient exchange between the fungus and the host plant. Thus, there is contradictory evidence regarding the reward mechanism between $\mathrm{C}$ and $\mathrm{N}$ in whole plants in the soil. Also, what triggers the fungus to transfer $\mathrm{N}$ to the host is unknown.

Here, the results of many recent studies are discussed to present a new perspective on $\mathrm{N}$ uptake, transport, degradation, and transfer to the host plant roots, and the use of $\mathrm{N}$ forms by the germinating spores of $G$. intraradices.

\section{Forms of nitrogen uptake and its underlying mechanism in arbuscular mycorrhizal fungi}

The ERM of AM fungi associated with the roots of the host plant absorb various forms of $\mathrm{N}$ from the surroundings (Figure 1). Johnsen et al. [9] proved that G. intraradices grown in a medium containing ${ }^{15} \mathrm{NH}_{4}^{+}$generated abundant free AA in the ERM, among which glutamate (Glu), glutamine (Gln), asparagine (Asn), aspartate, and alanine were predominantly produced and labeled with ${ }^{15} \mathrm{~N}$. These results

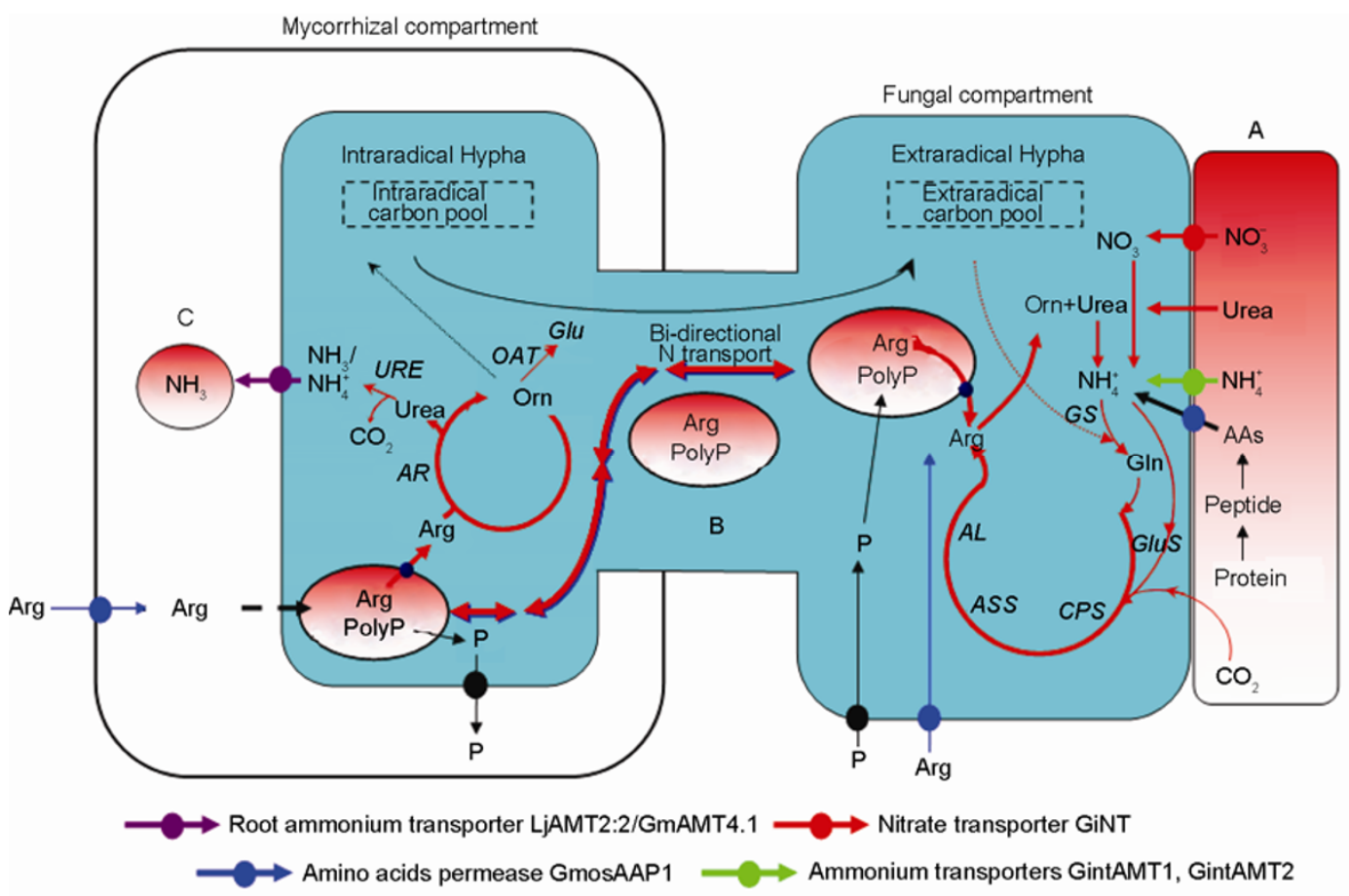

Figure 1 A model of $\mathrm{N}$ uptake, translocation, degradation, and transfer in the symbiotic system between Ri T-DNA carrot root and the arbuscular mycorrhizal (AM) fungus, G. intraradices. A, Various $\mathrm{N}$ sources $\left(\mathrm{NO}_{3}{ }^{-}, \mathrm{NH}_{4}{ }^{+}\right.$, amino acids, peptide, and protein) are taken up, assimilated, and incorporated into arginine (Arg) by the extraradical mycelium (ERM). Ammonium-, nitrate-, and amino acid-transporters and permease (encoded by the genes GiNT, GintAMT1, GintAMT2, and GmosAAP1) in the ERM of AM fungi participate in N absorption processes. The glutamine synthetase-glutamate synthase pathway (GS-GOGAT) is involved in ammonium assimilation and the anabolic arm of the urea cycle (involving the genes GiCPS, GiASS, and GiAL) is responsible for Arg biosynthesis. B, The accumulated Arg as well as polyphosphate (PolyP) is then bidirectionally translocated along the coenocytic fungal hyphae from the ERM to the intraradical mycelium (IRM) or from the mycorrhizal compartment tissue to the ERM. C, Arg is catabolized through the catabolic arm of the urea cycle (involving the genes GiCAR1, GiOAT1, and GiURE) in the IRM, releasing $\mathrm{NH}_{3} / \mathrm{NH}_{4}{ }^{+}$into arbuscules. Because of the acidic environment in the periarbuscular space, the ratio shifts toward $\mathrm{NH}_{4}{ }^{+}(99.99 \%)$. The $\mathrm{NH}_{4}{ }^{+}$ion is deprotonated prior to its transport across the plant membrane via the AMT protein and released in its uncharged $\mathrm{NH}_{3}$ form into the plant cytoplasm. The $\mathrm{NH}_{3} / \mathrm{NH}_{4}{ }^{+}$acquired by the plant is either transported into adjacent cells or immediately incorporated into amino acids. Figure modified from Govindarajulul et al. [24] and Jin et al. [25]. GS, Glutamine synthetase; GluS, glutamate synthase; CPS, carbamoyl-phosphate synthase; ASS, argininosuccinate synthase; AL, arginosuccinate lyase; AR, arginase; OAT, ornithine aminotransferase. 
indicated that AM fungi can uptake and assimilate exogenous $\mathrm{NH}_{4}{ }^{+}$. However, the uptake of ${ }^{15} \mathrm{NO}_{3}{ }^{-}$as the sole $\mathrm{N}$ source by the ERM of the fungi significantly decreased the ${ }^{15} \mathrm{~N}$ enrichment of these amino acids. Moreover, when both $\mathrm{NH}_{4}{ }^{+}$and $\mathrm{NO}_{3}{ }^{-}$were present in the medium, the AM fungi preferentially used the former [11], signifying that it is more energy efficient for the ERM to assimilate $\mathrm{NH}_{4}{ }^{+}$than $\mathrm{NO}_{3}{ }^{-}$. As well, these results suggested that a reduced-N source, such as $\mathrm{NH}_{4}^{+}$or a downstream $\mathrm{N}$ metabolite, might repress $\mathrm{NO}_{3}{ }^{-}$influx at both the transcriptional and posttranslational levels, like in plants [33]. Nevertheless, $\mathrm{NO}_{3}{ }^{-}$is more mobile in soil and more readily accessible to the roots of the host plant.

For organic $\mathrm{N}$ uptake, Leigh et al. [34] and Hodge et al. [35] showed that the AM fungus Glomus hoi enhanced degradation of organic residues and $\mathrm{N}$ uptake by the host plant. For example, up to one-third of the patch $\mathrm{N}$ was captured by the AM fungus and transferred to the plant, so approximately $20 \%$ of plant $\mathrm{N}$ may have been patch-derived. Nayyar et al. [36] also reported that AM fungi species enhanced $\mathrm{N}$ mineralization from organic residues to different levels, e.g., Glomus clarum hyphae recovered and translocated up to $25 \%$ of mineralized $N$ to Russian wild rye. Furthermore, using a sterilized split Petri dish system with a mycorrhizal Ri T-DNA carrot root compartment and a fungal compartment, we found that the ERM of the AM fungus $G$. intraradices was able to use polypeptides (tri-alanine) and soluble proteins (bovine serum albumin) [29]. However, the mechanisms by which AM fungi use organic residues or proteins remain unclear. Among the $\mathrm{N}$ sources taken up by the AM fungi, urea, or $\mathrm{NH}_{4}{ }^{+}$were absorbed more rapidly than $\mathrm{NO}_{3}{ }^{-}, \mathrm{AA}$, and proteins [25].

In terms of the mechanism of $\mathrm{N}$ uptake, assimilation of $\mathrm{NH}_{4}{ }^{+}$is the principal means of $\mathrm{N}$ absorption in AM fungal systems. The uptake of $\mathrm{NH}_{4}{ }^{+}$by the fungi is probably mediated by a specific carrier [37]. This mechanism is supported by characterization of GintAMT1, which encodes the high-affinity $\mathrm{NH}_{4}^{+}$transporter in the AM fungus $G$. intraradices [38]. Whereas GintAMT1 plays a role in mycelial uptake of $\mathrm{NH}_{4}^{+}$at low concentrations in the medium, GintAMT2, which is constitutively expressed in N-limiting conditions and transiently induced after exposure to different $\mathrm{N}$ sources, plays a role in retaining the $\mathrm{NH}_{4}{ }^{+}$derived from the metabolism of different $\mathrm{N}$ sources [39]. The coordination of the two AMTs effectively promoted $\mathrm{NH}_{4}{ }^{+}$assimilation and incorporation into AA.

Meanwhile, $\mathrm{NO}_{3}{ }^{-}$uptake is linked to a $\mathrm{H}^{+}$symporter that alkalinizes the external medium. As in most plants, mycorrhizal roots and the extraradical hyphae appear to use a similar mechanism for $\mathrm{NO}_{3}{ }^{-}$uptake, because alkalinization of the mycorrhizosphere and hyphosphere still occurred when $\mathrm{NO}_{3}{ }^{-}$was the sole $\mathrm{N}$ form $[8,40]$. Tian et al. [28] amplified the sequence of a high-affinity nitrate transporter (GiNT) from $G$. intraradices. Kaldorf et al. [41] reported that after
$\mathrm{NO}_{3}{ }^{-}$uptake, a nitrate reductase catalyzing the formation of $\mathrm{NH}_{4}{ }^{+}$was differentially expressed in the AM symbiosis of maize, suggesting that $\mathrm{NO}_{3}{ }^{-}$may be transferred from the fungus to the plant. However, Govindarajulu et al. [24] showed that the fungus could absorb nitrate but could not transfer it to the plant. More recently, Tisserant et al. [42] reported that nitrate permease and nitrate reductase were upregulated in roots of $G$. intraradices-colonized Medicago truncatula, indicating that nitrate could be absorbed and assimilated by AM fungi rather than being directly transferred to the host.

Organic forms of N, such as Glu, Gln, Asn, and alanine are the most abundant AA available for uptake by soil organisms, with concentrations ranging between 1 and $10 \mu \mathrm{g}$ per g dry soil [43]. Cappellazzo et al. [44] characterized a sequence encoding an AA permease (GmosAAP1) from the AM fungus $G$. mosseae. Their results suggested that GmosAAP1 plays a role in direct amino acid uptake from the soil, consistent with previous findings on uptake of Arg and other AAs [25]. Furthermore, Tisserant et al. [42] found that AAs-transporting genes are highly expressed in ERM and IRM, according to the transcriptome of the AM fungus G. intraradices (DAOM 197198). These findings indicated that the symbionts can take up AAs from both soils and the interfacial apoplast. For protein utilization, other mycorrhizal fungi (e.g., ericaceous and ectomycorrhizal) excrete extracellular proteases to degrade proteins into AAs, and subsequently absorb them via AAs transporters $[45,46]$. To date, however, protease excretion by AM fungi has not been reported.

Taken together, in contrast with ectomycorrhizal fungi [47], analyses of gene expression in AM fungi indicate that $\mathrm{NH}_{4}{ }^{+}-\mathrm{NO}_{3}{ }^{-}$, and AAs-transporters and permeases in the ERM may play a role in the active $\mathrm{N}$ absorption process.

\section{Nitrogen assimilation via GS/GOGAT path- way in arbuscular mycorrhizal fungi}

After $\mathrm{NH}_{4}{ }^{+}$is taken up by AM fungi, it is incorporated into AA via the GS/GOGAT cycle. Govindarajulu et al. [24] provided evidence that $\mathrm{N}$ is assimilated in the ERM of $G$. intraradices via the GS-GOGAT pathway by measuring mRNA levels for key enzymes in the ERM and intraradical mycelium (IRM) tissues using quantitative real-time polymerase chain reaction techniques. They also analyzed the expression of a putative nicotinamide adenine dinucleotide (NAD)-dependent glutamate dehydrogenase (GDH) gene, which was down-regulated in the ERM tissue supplied with either $\mathrm{NO}_{3}^{-}$or $\mathrm{NH}_{4}^{+}$in the ERM compartment, consistent with this enzyme having a catabolic role [48]. This means that when a $\mathrm{C}$ source is scarce, Glu is catabolized through an NAD-dependent GDH to produce $\mathrm{C}$ skeletons to replenish the tricarboxylic acid cycle. Breuninger et al. [12] 
showed that GS was constitutively expressed during all stages of the fungal life cycle, whereas exposure to $\mathrm{NH}_{4}{ }^{+}$ resulted in a general increase in GS activity when compared with that in hyphae grown with $\mathrm{NO}_{3}{ }^{-}$as the sole $\mathrm{N}$ source. This finding was also consistent with the assimilation of inorganic $\mathrm{N}$ through the GS-GOGAT pathway in the ERM. For the two GS isoforms GiGS1and GiGS2, the former serves at lower exogenous $\mathrm{N}$ and the latter is rapidly induced for assimilation when $\mathrm{N}$ is present at high levels [28]. More recently, analyses of the IRM transcript profile confirmed the role of the GS-GOGAT pathway in assimilation of $\mathrm{NH}_{4}{ }^{+}$[42]. Although the end products of the GS-GOGAT pathway, Glu/Gln, could be the form of $\mathrm{N}$ translocated in the ectomycorrhizal fungi, this two molecules do not play the same role as in AM fungi.

\section{Biosynthesis and translocation of arginine from extraradical mycelium to intraradical my- celium of arbuscular mycorrhizal fungi}

The Glu/Gln that accumulates via activity of the GS-GOGAT pathway is not directly transported by AM fungal hyphae, but is mainly used in Arg biosynthesis. The mechanism for $\mathrm{N}$ assimilation and transport to the host plant via the AM fungi was proposed by Bago et al. [23] and proved by Jin et al. [25] (Figure 1). In vitro mycorrhizae of G. intraradices and $\mathrm{Ri} \mathrm{T}$-DNA-transformed carrot roots grown in two-compartment Petri dishes containing ${ }^{15} \mathrm{NH}_{4} \mathrm{Cl}$ synthetic medium on the fungal side generated a high level of ${ }^{15} \mathrm{~N}$ labeling in the free AAs in the ERM, among which Arg was most abundant, accounting for more than $90 \%$ of the total ${ }^{15} \mathrm{~N}$ in the free AAs. When $\left[\mathrm{U}_{-}{ }^{13} \mathrm{C}\right.$ ] Arg (MTBSTFA derivative with an $\mathrm{m} / \mathrm{z}$ of 448) was used as the labeled substrate in the fungal compartment, it remained intact in the mycorrhizal root tissue $(\mathrm{m} / \mathrm{z}$ of 448$)$ as well as in the ERM, confirming that Arg was either taken up or synthesized via the ERM and transported intact to the IRM. This finding was consistent with the results of other $\left[\mathrm{U}_{-}-{ }^{13} \mathrm{C} / \mathrm{U}_{-}{ }^{15} \mathrm{~N}\right] \mathrm{Arg}$ labeling experiments [26]. These results indicated that AM fungi take up $\mathrm{N}$, incorporate it into $\mathrm{Arg}$, and then transport it to the IRM in the form of organic N. When the AM fungus $G$. intraradices was inoculated onto the host plant Allium fistulosum grown in a three-part pot culture system (data not published) with $4 \mathrm{mmol} \mathrm{L}^{-1}$ of several different forms of exogenous $\mathrm{N}$ in the fungal compartment, the capacity of the ERM to absorb the different $\mathrm{N}$ forms and produce Arg was ranked as follows: urea $>\mathrm{Gln}>\mathrm{NH}_{4} \mathrm{NO}_{3}>\mathrm{Arg} / \mathrm{Gly}>\mathrm{NH}_{4} \mathrm{Cl}>$ $\mathrm{KNO}_{3}$. In the same experimental system, the amount of Arg formed in the mycorrhizal roots was ranked as follows: Arg $>$ Gln $>$ Urea $>\mathrm{NH}_{4} \mathrm{NO}_{3}>\mathrm{Gly}>\mathrm{NH}_{4} \mathrm{Cl}>\mathrm{KNO}_{3}$, inconsistent with the results of a previous study [25]. These results indicate that urea was the most easily assimilated form of $\mathrm{N}$ by the ERM, but Arg and Gln taken up by the ERM resulted in higher levels of Arg in the mycorrhizal root. These findings suggested that the energy and $\mathrm{C}$ costs of $\mathrm{N}$ assimilation and incorporation into Arg and its translocation to the mycorrhizal root might be greater than those associated with direct uptake of organic $\mathrm{N}$ in the form of Arg and Gln.

Thus, the pathway to biosynthesize Arg in AM fungi is assumed to be an extended route of $\mathrm{N}$ uptake and assimilation. After $\mathrm{NH}_{4}^{+}$uptake and assimilation via the GS/ GOGAT cycle, the assimilated $\mathrm{N}$ is incorporated into Arg through the urea cycle. Cruz et al. [27] measured the activities of the key enzymes involved in Arg biosynthesis, such as glutamine synthetase and argininosuccinate synthetase, assuming that the pathway of Arg biosynthesis involves reactions leading to ornithine (Orn) synthesis. This reaction requires Glu, the carbamoyl group of carbamoyl phosphate produced from bicarbonate, ammonia $\left(\mathrm{NH}_{3}\right)$ (released from Glu), and phosphate (from ATP). These compounds are transferred to Orn yielding citrulline. The ureido group of citrulline is then condensed with an aspartate amino group by argininosuccinate synthetase into argininosuccinate, which is then cleaved by argininosuccinate lyase to produce Arg and fumaric acid [49]. Evidence for Arg biosynthesis was also obtained by Tian et al. [28], who analyzed the expressions of the genes GiCPS and GiAL encoding carbamoyl phosphate synthetase (EC 6.3.5.5) and the partial sequence of the putative argininosuccinate lyase (EC 4.3.2.1). The amplified full-length coding sequence of argininosuccinate synthetase (GiASS, EC 6.3.4.5) was essential for Arg formation, as demonstrated by complementation analysis of the arginine-auxotroph Saccharomyces cerevisiae mutant YOLO58W, which lacked the ARG1 gene. The timing and location of the observed transcriptional changes were consistent with the expectation that Arg synthesis would be up-regulated in the ERM but not in the IRM after $\mathrm{N}$ addition, and that Arg accumulation in the ERM would not repress Arg synthesis genes by the general AAs control system. Therefore, Arg in the ERM functions more as a transport molecule than a storage compound. More recently, Tisserant et al. [42] reported that the transcripts encoding enzymes associated with Arg biosynthesis were highly expressed in the ERM and IRM. From these experiments, we can conclude that Arg biosynthesis plays a pivotal role in $\mathrm{N}$ assimilation for further translocation and transfer in the AM symbiosis.

Thereafter, Arg biosynthesized in the ERM through the anabolic arm of the urea cycle is possibly transported with polyphosphate (PolyP) along the motile tubular vacuole to the IRM. Arg is bidirectionally translocated to potential $\mathrm{N}$-limited sites in the mycelium of AM fungi either from the ERM to the IRM or from the mycorrhizal root to the ERM [26], indicating that an " $\mathrm{N}$ demand" mechanism may play a role in triggering Arg transport. In doing so, AM fungi can transfer $\mathrm{N}$ and $\mathrm{P}$ from one plant to another through a mycorrhizal mycelium network, thus promoting effective $\mathrm{N}$ and P-use over a wide area. In contrast, Smith and Smith [50] suggested that ionized $\mathrm{P}$ in polyP is balanced by inorganic 
cations such as $\mathrm{K}^{+}$and $\mathrm{Mg}^{2+}$, with no need for $\mathrm{Arg}^{+}$to perform this role. Although this type of charge balance mechanism might be involved in co-transportation of $\mathrm{P}$ and other mineral elements, Arg cannot be excluded from combining with $\mathrm{P}$ since Arg dissolves readily in a solution containing equal molar concentrations of inorganic $\mathrm{P}$ and short chain polyP. Meanwhile, C sources (lipid and glycogen) in the vacuoles, supplied from the IRM, are transported in the reverse direction along the mycelium to the ERM [51]. Recently, Fellbaum et al. [30] found that the C supply to the host plant triggers the uptake and transport of $\mathrm{N}$ in the symbiosis. However, Olsson et al. showed that the allocation of $\mathrm{C}$ to the AM fungus depends on the $\mathrm{N}$ status of the mycorrhizal root [32], indicating that the stoichiometry of $\mathrm{C}$ and $\mathrm{N}$ constrain nutrient exchange between the fungus and the host plant.

\section{Degradation of translocated arginine and re- lease of nitrogen in intraradical mycelium}

Generally, Arg breakdown starts with the conversion of Arg to Orn and urea by arginase. Orn aminotransferase (EC 2.6.1.13) and Orn decarboxylase (EC4.1.1.17) catalyze the breakdown of Orn [52-54]. In terms of Arg catabolism in AM fungi (Figure 1), Jin [26] showed that once Arg was translocated to the potential N-limited sites in the mycelium of AM fungi, either from the ERM to the IRM or from the mycorrhizal root to the ERM, it was further degraded into Orn and urea. This conclusion was drawn because either $\left[\mathrm{U}_{-}{ }^{13} \mathrm{C}\right]$ or $\left[\mathrm{U}_{-}{ }^{15} \mathrm{~N} / \mathrm{U}_{-}{ }^{13} \mathrm{C}\right]$ Orn was present in the mycorrhizal root tissues when either $\left[\mathrm{U}_{-}{ }^{13} \mathrm{C}\right]$ or $\left[\mathrm{U}_{-}{ }^{15} \mathrm{~N} / \mathrm{U}-{ }^{13} \mathrm{C}\right] \mathrm{Arg}$ was labeled in the fungal compartment. Evidently, formation of Orn reflects the ongoing activities of Arg translocation and degradation through the urea cycle in the AM fungal mycelium. Thereafter, $\mathrm{N}$ released from Arg breakdown is transferred to the host plant or recycled to biosynthesize other AAs and nucleotides necessary for fungal growth.

The evidence obtained through analyses of gene expression and key enzyme activities involved in Arg breakdown further confirmed the role of the catabolic arm of the urea cycle. Govindarajulu et al. [24] showed that the catabolic arm of the urea cycle played a role in controlling the transcript levels of genes with a high similarity to Orn aminotransferase, urease accessory protein, and $\mathrm{NH}_{4}{ }^{+}$transporters, which were preferentially expressed in the IRM of G. intraradices. Cruz et al. [27] found enzymatic evidence of Arg turnover, including the specific enzyme activity of arginase and urease in the IRM. They also found that decreased Arg production in the ERM and subsequent reduction in Arg supply to the IRM resulted in decreased activities of enzymes involved in Arg catabolism. They noted that the regulation of the urea cycle have a negative effect of external $\mathrm{NH}_{4}^{+}$availability on the catabolic arm in the ERM, or that either internal $\mathrm{NH}_{4}^{+}$or a downstream metabolite, possibly Arg, negatively affected $\mathrm{NH}_{4}{ }^{+}$uptake and assimilation in the IRM. These findings revealed that the catabolic activity of the urea cycle in the mycorrhizal roots depends on the arrival of Arg from the ERM. Furthermore, Tian et al. [28] obtained an arginase (GiCAR1, EC 3.5.3.1) sequence and also confirmed the function of the cloned urease (GiURE) from $G$. intraradices in the use of urea as a $\mathrm{N}$ source [28], suggesting that the activities of genes involved in Arg breakdown and $\mathrm{NH}_{4}{ }^{+}$release should increase in the IRM but not the ERM after N supply. Thus, strong expressions of genes encoding arginase, urease, and the urease accessory protein in the IRM might degrade Arg and result in greater release of $\mathrm{NH}_{4}{ }^{+}$[42].

As such, the synchronization between the spatially separate anabolic and catabolic arms of the urea cycle can maintain efficient biosynthesis and translocation of Arg in the AM fungal mycelium. Such rapid assimilation and incorporation of inorganic $\mathrm{N}$ into Arg through the anabolic arm of the urea cycle can prevent toxic accumulation of ammonium ions, and also ensure that hyphal growth demands are satisfied before transfer of $\mathrm{N}$ to the host plant. Meanwhile, translocation of Arg along the hyphae not only satisfies the nutrient needs of coenocytic hyphal branching, but also plays the most important role in the nutrient transfer pathway to the host plant, by which AM fungi can continuously absorb $\mathrm{N}$ from the medium to transport it to the host plant rather than accumulate $\mathrm{N}$ for its own requirements. For example, Jin et al. [25] reported that even though most of the root biomass had formed before ${ }^{15} \mathrm{~N}$ labeling, the ${ }^{15} \mathrm{~N}$ content in the roots still reached a value of $50.4 \% \pm 7.4 \%$, indicating that most of the $\mathrm{N}$ taken up by the roots during the labeling period came from the fungus.

\section{Transfer of $\mathrm{NH}_{3} / \mathrm{NH}_{4}{ }^{+}$released into ar- buscules of arbuscular mycorrhizal fungi to host via ammonium transporters}

As shown in Figure 1, the $\mathrm{NH}_{4}{ }^{+}$derived from Arg is either incorporated into other AAs in the IRM or transferred to the roots of the host plant. However, the mechanisms involved in the transfer of ammonia or ammonium are a matter of debate. Tanaka and Yano [55] found that $\mathrm{N}$ transferred to Zea mays L. depended on the N sources supplied to the hyphae of G. aggregatum Schenck \& Smith. For example, $74 \%$ of shoot-N was derived from slow-release urea added to the hyphal compartment while only $2.9 \%$ was derived from $\mathrm{NO}_{3}{ }^{-}$. They concluded that the mycorrhizal fungus can rapidly deliver $\mathrm{NH}_{4}{ }^{+}$to the plants, and that while the fungus can absorb $\mathrm{NO}_{3}{ }^{-}$, it cannot transfer it to the plant. The underlying reason may be the low assimilation rate of $\mathrm{NO}_{3}^{-}$.

In general, the transfer of $\mathrm{NH}_{4}{ }^{+}$to the cytoplasm of plant cells is achieved via active transportation and other non-specific channels, such as aqua-ammoniaporins or the 
voltage-dependent cation system. Non-specific channels might also contribute to $\mathrm{NH}_{3}$ transport from the interfacial apoplast to the plant cell cytoplasm [56]. Govindarajulu et al. [24] reported that in an AM symbiosis, a $G$. intraradices gene showing high similarity to a known $\mathrm{NH}_{4}{ }^{+}$transporter gene (GmAMT 4.1) was overexpressed in the IRM. The GS activity in the roots increased with increasing $\mathrm{NH}_{4}{ }^{+}$availability on the fungal side, and corresponded to the metabolism of $\mathrm{NH}_{4}{ }^{+}$produced during urea degradation in the IRM. These findings indicated that $\mathrm{NH}_{4}{ }^{+}$is transferred from the IRM to the plant cell. Furthermore, Guether et al. [57] reported that $\mathrm{NH}_{3} / \mathrm{NH}_{4}{ }^{+}$was released into the arbuscules from Arg,which is transported from the extra- to the intraradical fungal structure. Then, the Lotus japonicus $\mathrm{NH}_{4}{ }^{+}$transporter encoded by LjAMT2;2 bound charged $\mathrm{NH}_{4}{ }^{+}$in the apoplastic interfacial compartment and released the unchanged $\mathrm{NH}_{3}$ into the plant cytoplasm. This is consistent with the findings of Kobae et al. [58], who reported that the released $\mathrm{NH}_{4}{ }^{+}$was transferred across the periarbuscular membrane to the host cortical cells, and that during this process, the $\mathrm{NH}_{4}^{+}$ transporter gene (GmAMT 4.1) was abundantly transcribed and specifically expressed in the arbusculated cortical cells. The tomato root transcriptome results reported by Ruzicka et al. [59] further suggested that mycorrhizal plants took up and assimilate more $\mathrm{N}$ than non-mycorrhizal plants, and that $\mathrm{N}$ uptake of mycorrhizal plants was facilitated through the mycorrhizal-specific AMT4 and AMT5 $\mathrm{NH}_{4}{ }^{+}$transporters. However, the majority of fungal transporters and many of the chemical gradients and energetic drivers of the symbiotic interchanges are unknown.

Meanwhile, another study showed that when $\mathrm{N}$ released from Arg degradation was transferred to the host plant, the Arg-originated $\mathrm{C}$ was not incorporated into the host $\mathrm{C}$ pool, but remained in the IRM. Such a mode of nutrient exchange is the most economical for the AM fungal symbiont. After Arg degradation, Orn was recycled into Glu and Gln as C donors since $\left[\mathrm{U}_{-}{ }^{13} \mathrm{C}\right]$ Arg translocation from the ERM to the mycorrhizal roots resulted in ${ }^{13} \mathrm{C}$ labeling of Glu and Gln in spite of their low levels, whereas other AAs displayed negligible ${ }^{13} \mathrm{C}$ labeling [26]. The results of Tian et al. [28] further verified these findings, since there were increased expressions of the two ornithine aminotransferase sequences (GiOAT1, GiOAT2), but not the putative ornithine decarboxylase $(G i O D C)$, after an increase in $\mathrm{N}$ supply. These findings suggested that Orn is converted to Glu. Therefore, a cycle involving Orn appears to be more efficient for supplying materials for Arg biosynthesis and $\mathrm{C}$ recycling in the AM symbiosis.

\section{Utilization of nitrogen sources via germinated arbuscular mycorrhizal fungal spores}

Carbon metabolism [60], $\mathrm{N}$ assimilation, and $\mathrm{N}$ metabolism [61] in AM fungal spores have been well documented. Alt- hough exogenous $\mathrm{N}$ is not required for pre-symbiotic growth, it can be used for the de novo biosynthesis of amino acids. Among the various $\mathrm{N}$ sources, $\mathrm{NH}_{4}{ }^{+}$and urea were assimilated more rapidly than $\mathrm{NO}_{3}{ }^{-}$and AAs [61]. Root exudates did not stimulate the uptake and utilization of exogenous $\mathrm{NH}_{4}{ }^{+}$; however, they did stimulate expressions of genes encoding Glu dehydrogenase, a urease accessory protein, and Orn aminotransferase in germinating spores of G. intraradices. The results of that study indicated that germinating spores break down stored $\mathrm{N}$ (Arg or proteins) during pre-symbiotic growth. Moreover, Arg may be involved in transporting and translocating $\mathrm{N}$ from the spore along the developing hyphae in the symbiotic stage. In such cases, germinating AM spores combine the $\mathrm{C}$ skeletons derived from the degradation of internally stored lipids with the $\mathrm{N}$ released from stored $\mathrm{N}$ compounds (Arg or proteins) for the de novo biosynthesis of free AAs, among which serine and glycine are predominant [62]. This is consistent with the large flux in the glyoxylate cycle and the use of lipids as a C source for carbohydrate and AAs biosyntheses [63].

Exogenous inorganic and organic forms of $\mathrm{N}$ and glucose are also readily taken up and incorporated into AAs in the spores. De novo biosynthesis of free AAs in AM spores increased greatly after the uptake of exogenous $\mathrm{NH}_{4}{ }^{+}$, urea, and $\mathrm{NO}_{3}^{-}$. In cases of a low $\mathrm{C}: \mathrm{N}$ ratio (no exogenous glucose), Asn was the predominant amino acid in the AM spores. Asn may play a role in the $\mathrm{N}$ and $\mathrm{C}$ reserves for AAs metabolism during spore germination, suggesting that the main $\mathrm{C}$ sources for AAs biosynthesis are from the products of stored lipid degradation and the glyoxylate cycle. In contrast, at a high C:N ratio (available exogenous glucose), Arg was predominantly produced and further incorporated into proteins in germinating AM spores [62]. This was consistent with the findings of Tisserant et al. [42], who reported that the transcripts encoding enzymes associated with Arg biosynthesis were highly expressed in germinated spores of the AM fungus $G$. intraradices. In such cases, exogenous glucose taken up by spores supplies more $\mathrm{C}$ skeletons and reductants through glycolysis, the tricarboxylic acid cycle, and the urea cycle, thereby allowing greater AAs biosynthesis.

Additionally, $\mathrm{N}$ could be required to induce PolyP synthetic activity in germ tubes [64] because it is required during germination and germ tube growth. The influence of $\mathrm{N}$ on PolyP metabolism is complicated; $\mathrm{NO}_{3}^{-}$stimulated not only PolyP accumulation in the hyphae, but also spore germination and growth of the germ tube, whereas $\mathrm{NH}_{4}{ }^{+}$did not. The beneficial effect of $\mathrm{NO}_{3}^{-}$on germ tube growth can be explained by its nutritional role. Further experiments will be necessary to determine whether AMF can use $\mathrm{NH}_{4}{ }^{+}$as an effective $\mathrm{N}$ source for growth.

A model of the major pathway for $\mathrm{C}$ and $\mathrm{N}$ uptake and metabolism in the germinating AM spores of $G$. intraradices is outlined in Figure 2. 


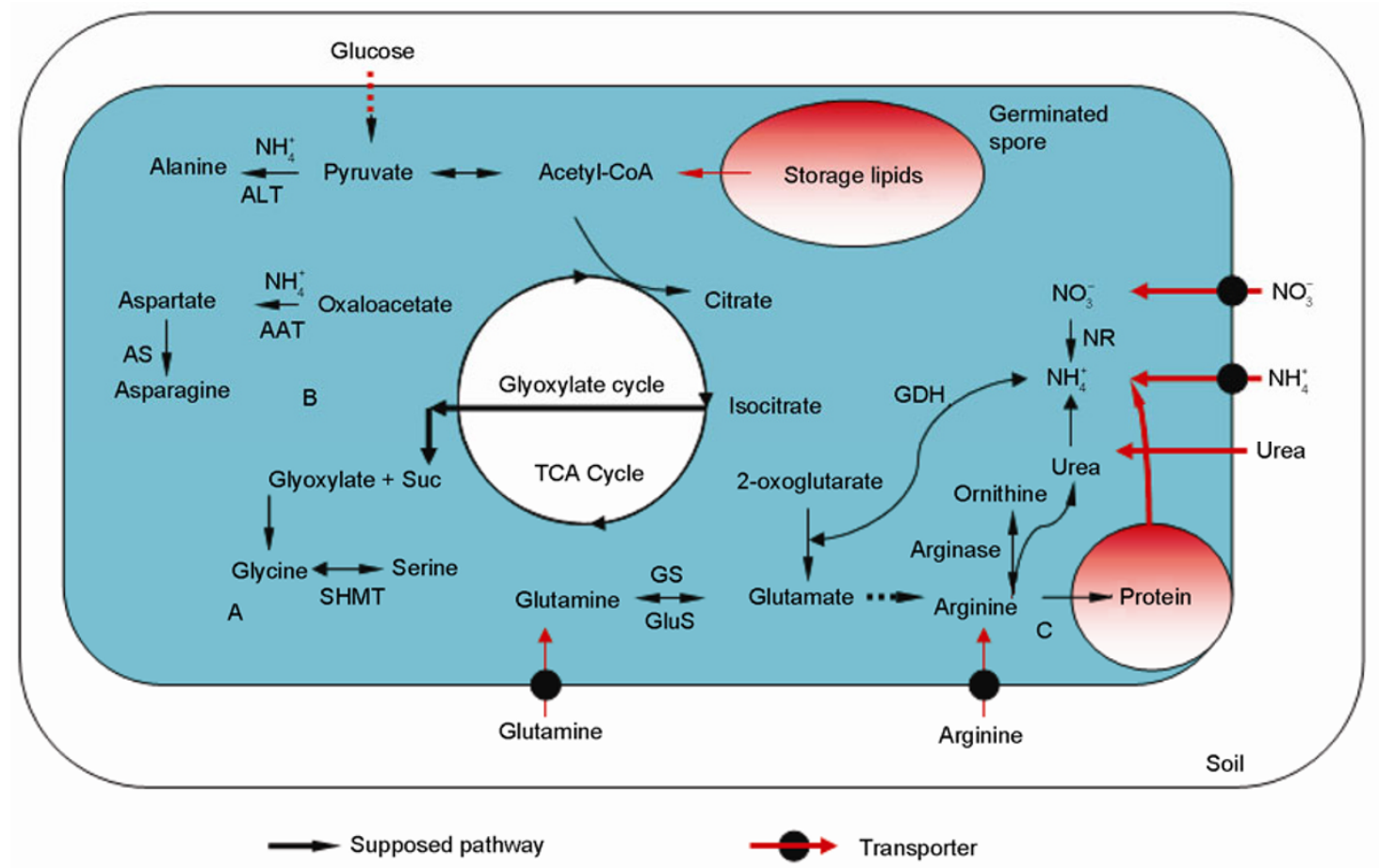

Figure 2 A model of the major metabolic pathway for nitrogen $(\mathrm{N})$ and carbon $(\mathrm{C})$ in germinating spores of arbuscular mycorrhizal (AM) fungi G. intraradices. $\mathrm{A}$, In the absence of exogenous $\mathrm{N}$ sources, storage $\mathrm{N}$ compounds (proteins), together with storage lipids as $\mathrm{C}$ sources, are used to produce amino acids (predominantly glycine and serine) through the glyoxylate cycle. B, External $\mathrm{N}$ sources, such as $\mathrm{NH}_{4}{ }^{+}, \mathrm{NO}_{3}{ }^{-}$, urea, and amino acids (glutamine and arginine) are taken up and assimilated to synthesize amino acids. These amino acids are usually asparagine when an exogenous $\mathrm{C}$ source is absent, and arginine $(\mathrm{C})$ when glucose is available as the $\mathrm{C}$ source for spore germination. Assimilated $\mathrm{N}$ can then be stored and incorporated into proteins in the AM germinating spores. Figure modified from Gachomo et al. [61]. ALT, alanine transaminase; AS, asparaginase; AAT, aspartate aminotransferase; GDH, glutamate dehydrogenase; GluS, glutamate synthase; GS, glutamine synthetase; NR, nitrate reductase; SHMT, serine hydroxymethyltransferase.

\section{Conclusion}

A significant breakthrough was made in elucidating $\mathrm{N}$ uptake, translocation, and transfer in AM fungal symbiosis through in vitro cultures of Ri T-DNA carrot root colonized with $G$. intraradices (Figures 1 and 2). The validity of using root-organ cultures to study the most challenging questions in the biochemical, genetic, and physiological relationships between AM fungi and their hosts is supported by finding that these organ tissues have the same mycorrhizal characteristics and fungal capabilities to complete their life cycles [65]. However, in this system, the plant host is replaced by a root-organ and the symbiotic effect on the plant is altered by the absence of photosynthetic tissues. Therefore, the measurements and analyses of $\mathrm{N}$ uptake, transport, and transfer in the non-sterilized soil-fungi-whole plant system are more complex. In addition, not all Glomeromycota show the same mechanism of $\mathrm{N}$ uptake and transport as described here. For example, Geosiphon pyriforme does not form mycorrhizae.

It has been demonstrated that AM fungi can deliver substantial amounts of $\mathrm{N}$ to the host plant, with an estimated $21 \%$ of total $\mathrm{N}$ taken up by the fungal ERM being transferred to roots in root organ culture [11] and $74 \%$ of the total $\mathrm{N}$ in the leaves of $Z$. mays coming from the fungal ERM with supplied with urea [55]. However, the hyphal contribution of $\mathrm{N}$ may vary with the functional compatibility of AM fungal isolates or the levels or forms of $\mathrm{N}$ available to the fungus. For example, the beneficial mycorrhizal effect is reduced under large quantities of $\mathrm{N}$ fertilizer $[50,66]$. Meanwhile, Smith raised the question as to whether AM fungi can contribute significantly to the $\mathrm{N}$ nutrition of the plant when $\mathrm{N}$ is so highly mobile in the soil [50]. Besides, the impacts of salt and water availability on $\mathrm{N}$ assimilation and translocation in the symbiotic relationship are still unclear [67]. Thus, several questions remain: (i) How does the $\mathrm{N}$ status of the host plant and/or soil conditions influence the bidirectional translocation of $\mathrm{N}(\mathrm{Arg})$ along the mycelium of AM fungi? (ii) What are the contributions of the AM fungal pathway to the total $\mathrm{N}$ requirements of the symbionts, and what are the costs to the host plant? (iii) How does the stoichiometry of available N, P, and C in the symbiosis influence the outcomes of the interactions between AM fungi and the host plant in the soil? Progress in these areas will provide fundamental theoretical knowledge for using AM fungi as a biofertilizer and to understand the role of AM fungi in the N cycle of soil [68]. 
The authors thank Philip Pfeffer and Yair Sharchar-Hill for useful discussion, ideas, and reagents. This work was supported by the National Natural Science Foundation of China (Grant No. 30970101).

1 Smith S E, Read D J, eds. Mycorrhizal Symbiosis. London, UK: Academic Press, 2008

2 Abdel Latef A A H. Influence of arbuscular mycorrhizal fungi and copper on growth, accumulation of osmolyte, mineral nutrition and antioxidant enzyme activity of pepper (Capsicum annuum L.). Mycorrhiza, 2011, 21: 495-503

3 Piao H C, Liu C Q. Variations in nitrogen, zinc, and sugar concentrations in Chinese fir seedlings grown on shrubland and plowed soils in response to arbuscular mycorrhizae-mediated process. Biol Fertil Soils, 2011, 47: 721-727

4 Cheng X M, Baumgartner K. Arbuscular mycorrhizal fungi-mediated nitrogen transfer from vineyard cover crops to grapevines. Biol Fert Soils, 2004, 40: 406-412

5 Meding S M, Zasoski R J. Hyphal-mediated transfer of nitrate, arsenic, cesium, rubidium, and strontium between arbuscular mycorrhizal forbs and grasses from a California oak woodland. Soil Biol Biochem, 2008, 40: 126-134

6 McFarland J W, Ruess R W, Kielland K, et al. Cross-ecosystem comparisons of in situ plant uptake of amino acid-N and $\mathrm{NH}_{4}^{+}$. Ecosystems, 2010, 13:177-193

7 Tobar R, Azcón R, Barea J M. Improved nitrogen uptake and transport from ${ }^{15} \mathrm{~N}$ labelled nitrate by external hyphae of arbuscular mycorrhiza under water-stressed conditions. New Phytol, 1994, 126: 119-122

8 Bago B, Vierheilig H, Piché Y, Azcón-Aguilar C. Nitrate depletion and $\mathrm{pH}$ changes induced by the extraradical mycelium of the arbuscular mycorrhizal fungus Glomus intraradices grown in monoxenic culture. New Phytol, 1996, 133: 273-280

9 Johansen A, Finlay R D, Olsson P A. Nitrogen metabolism of the external hyphae of the arbuscular mycorrhizal fungus Glomus intraradices. New Phytol, 1996, 133: 705-712

10 Hawkins H J, Johansen A, George E. Uptake and transport of organic and inorganic nitrogen by arbuscular mycorrhizal fungi. Plant Soil, 2000, 226: 275-285

11 Toussaint J P, St-Arnaud M, Charest C. Nitrogen transfer and assimilation between the arbuscular mycorrhizal fungus Glomus intraradices Schenck \& Smith and Ri T-DNA roots of Daucus carota L. in an in vitro compartmented system. Can J Microbiol, 2004, 50: 251-260

12 Breuninger M, Trujillo C G, Serrano E, et al. Different nitrogen sources modulate activity but not expression of glutamine synthetase in arbuscular mycorrhizal fungi. Fungal Genet Biol, 2004, 41: $542-552$

13 Azcón R, Ruiz-Lozano J M, Rodriguez R. Differential contribution of arbuscular mycorrhizal fungi to plant nitrate uptake of ${ }^{15} \mathrm{~N}$ under increasing N supply to the soil. Can J Bot, 2001, 79: 1175-1180

14 Shachar-Hill Y, Rolin D B, Pfeffer P E, et al. Uptake and transfer of $\mathrm{N}$ to the host by an arbuscular mycorrhizal (AM) fungus. Plant Physiol, 1997, 114(Suppl): 39, Abstr. 106

15 Vazquez M M, Barea J M, Azcon R. Impact of soil nitrogen concentration on Glomus spp.-Sinorhizobium interactions as affecting growth, nitrate reductase activity and protein content of Medicago sativa. Biol Fert Soils, 2001, 34: 57-63

16 Hodge A, Campbell C D, Fitter A H. An arbuscular mycorrhizal fungus accelerates decomposition and acquires nitrogen directly from organic material. Nature, 2001, 413: 297-299

17 Rolin D, Pfeffer P E, Douds D D, et al. Arbuscular mycorrhizal symbiosis and phosphorus nutrition: Effects on amino acid production and turnover in leek. Symbiosis, 2001, 30: 1-14

18 Rasmussen N, Lloyd D C, Ratcliffe R G, et al. ${ }^{31} \mathrm{P}$ NMR for the study of $\mathrm{P}$ metabolism and translocation in arbuscular mycorrhizal fungi. Plant Soil, 2000, 226: 245-253

19 Bago B, Pfeffer P E, Shachar-Hill Y. Carbon transport and metabo- lism in arbuscular mycorrhiza. Plant Physiol, 2000, 124: 949-957

20 Landis F C, Fraser L H. A new model of carbon and phosphorus transfers in arbuscular mycorrhizas. New Phytol, 2007, 177: 466-479

21 Smith S E, Gianinazzi-Pearson V, Koide R, et al. Nutrient transport in mycorrhizas: structure, physiology, and consequences for efficiency of the symbiosis. Plant Soil, 1994, 159: 103-113

22 Kaldorf M M, Schmelzer E, Bothe H. Expression of maize and fungal nitrate reductase in arbuscular mycorrhiza Mo. Plant-Microbe Interact, 1998, 11: 439-448

23 Bago B, Shachar-Hill Y, Pfeffer P E. Could the urea cycle be translocating nitrogen in the arbuscular mycorrhizal symbiosis? New Phytol, 2001, 149: 4-8

24 Govindarajulul M, Pfeffer P E, Jin H R, et al. Nitrogen transfer in the arbuscular mycorrhizal symbiosis. Nature, 2005, 435: 819-823

25 Jin H R, Pfeffer P E, Douds D D, et al. The uptake, metabolism, transport and transfer of nitrogen in an arbuscular mycorrhizal symbiosis. New Phytol, 2005, 168: 301-310

26 Jin H R. Arginine bi-directional translocation and breakdown into ornithine along the arbuscular mycorrhizal mycelium. Sci China Ser C-Life Sci, 2009, 52: 381-389

27 Cruz C, Egsgaard H, Trujillo C, et al. Enzymatic evidence for the key role of arginine in nitrogen translocation by arbuscular mycorrhizal fungi. Plant Physiol, 2007, 144: 782-792

28 Tian C J, Kasiborski B, Koul R, et al. Regulation of the nitrogen transfer pathway in the arbuscular mycorrhizal symbiosis: Gene characterization and the coordination of expression with nitrogen flux. Plant Physiol, 2010, 153: 1175-1187

29 Jin H R, Zhang P H, Jiang D H. Study on mechanism of arbuscular mycorrhizal fungi absorbing and transporting nitrogen from different sources to the host plant with isotopic tracing. Acta Pedol Sin, 2011, 48: 888-892

30 Fellbaum C R, Gachomo E W, Beesetty Y, et al. Carbon availability triggers fungal nitrogen uptake and transport in arbuscular mycorrhizal symbiosis. Proc Natl Acad Sci USA, 2012, 109: 2666-2671

31 Kiers E T, Duhamel M, Beesetty Y, et al. Reciprocal rewards stabilize cooperation in the mycorrhizal symbiosis. Science, 2011, 333: 880-882

32 Olsson P A, Burleigh S H, Van Aarle I M. The influence of external nitrogen on carbon allocation to Glomus intraradices in monoxenic arbuscular mycorrhiza. New Phytol, 2005, 168: 677-686

33 Coruzzi G M, Zhou L. Carbon and nitrogen sensing and signaling in plants: emerging matrix effects. Curr Opin Plant Biol, 2001, 4: 247-253

34 Leigh J, Hodge A, Fitter A H. Arbuscular mycorrhizal fungi can transfer substantial amounts of nitrogen to their host plant from organic material. New Phytol, 2009, 181: 199-207

35 Hodge A, Fitter A H. Substantial nitrogen acquisition by arbuscular mycorrhizal fungi from organic material has implications for $\mathrm{N}$ cycling. Proc Natl Acad Sci USA, 2010, 107: 13754-13759

36 Nayyar A A, Hamel C, Hanson K, et al. The arbuscular mycorrhizal symbiosis lins N mineralization to plant demand. Mycorrhiza, 2009, 19: 239-246

37 Botton B, Chalot M. Nitrogen assimilation: enzymology in ectomycrrhizas. In: Varma A, Hock B, eds. Mycorrhiza: Structure, Function, Molecular Biology and Biotechnology, 2nd Ed. Berlin: Springer-Verlag, 1999. 333-372

38 López-Pedrosa A, González-Guerrero M, Valderas A, et al. GintAMTi encodes a functional high-affinity ammonium transporter that is expressed in the extraradical mycelium of Glomus intraradices. Fungal Genet Biol, 2006, 43: 102-110

39 Pérez-Tienda J, Testillano P S, Balestrini R. GintAMT2, a new member of the ammonium transporter family in the arbuscular mycorrhizal fungus Glomus intraradices. Fung Genet Biol, 2011, 48: 1044-1055

40 Subramanian K S, Charest C. Acquisition of $\mathrm{N}$ by external hyphae of an arbuscular mycorrhizal fungus and its impact on physiological responses in maize under drought-stressed and well-watered conditions. Mycorrhiza, 1999, 9: 69-75

41 Kaldorf M M, Schmelzer E, Bothe H. Expression of maize and fungal 
nitrate reductase in arbuscular mycorrhiza Mo. Plant-Microbe Interact, 1998, 11, 439-448

42 Tisserant1 E, Kohler1 A, Dozolme-Seddas P. The transcriptome of the arbuscular mycorrhizal fungus Glomus intraradices (DAOM 197198) reveals functional tradeoffs in an obligate symbiont. New Phytol, 2012, 193: 755-769

43 Abuarghub S M, Read D J. The biology of mycorrhiza in Ericaceae. XII. Quantitative analysis of individual free amino acids in relation to time and depth in the soil profile. New Phytol, 1989, 108: 433-441

44 Cappellazzo G, Lanfranco L, Fitz Michael, et al. Characterization of an amino acid permease from the endomycorrhizal fungus Glomus mosseae. Plant Physiol, 2008, 147: 429-437

45 Leake J R, Read D J. The biology of mycorrhiza in Ericaceae. XIII. Some characteristics of extracellular proteinase of the ericoid endophyte Hymenoscyphus ericae. New Phytol, 1989, 112: 69-76

46 Cliquet J B, Murray P J, Boucaud J. Effect of the arbuscular mycorrhizal fungus Glomus fasciculatum on the uptake of amino nitrogen by Lolium perenne. New Phytol, 1997, 137: 345-349

47 Müller T, Avolio M, Olivi M, et al. Nitrogen transport in the ectomycorrhiza association: the Hebeloma cylindrosporum-Pinus pinaster model. Phytochem, 2007, 68: 41-51

48 Vallorani L, Polidori E, Sacconi C, et al. Biochemical and molecular characterization of NADP glutamate dehydrogenase from the ectomycorrhizal fungus Tuber borchii. New Phytol, 2002, 154: 779-790

49 Desh Pal S. Verma, Zhang C. Regulation of proline and arginine biosynthesis in plants. In: Singh B, ed. Plant Amino Acids Biochemistry and Biotechnology. New York: Marcel Dekker, 1999. 249-265

50 Smith S E, Smith F A. Roles of Arbuscular mycorrhizas in plant nutrition and growth: new paradigms from cellular to ecosystem scales. Annu Rev Plant Biol, 2011, 62: 227-250

51 Bago B, Zipfel W, Williams R M, et al. Translocation and utilization of fungal storage lipid in the arbuscular mycorrhizal symbiosis. Plant Physiol, 2002, 128: 108-124

52 Borsuk P, Dzikowska A, Empel J, et al. Structure of the arginase coding gene and its transcript in Aspergillus nidulans. Acta Biochim Pol, 1999, 46: 391-403

53 Dzikowska A, Kacprzak M, Tomecki R, et al. Specific induction and carbon/nitrogen repression of arginine catabolism gene of Aspergillus nidulans functional in vivo analysis of the otaA promoter. Fung Genet Biol, 2003, 38: 175-186

54 Wagemaker M J M, Eastwood D C, Van Der Drift C, et al. Argininosuccinate synthetase and argininosuccinate lyase: two ornithine cycle enzymes from Agaricus bisporus. Mycol Res, 2007, 111: 493-502
55 Tanaka Y, Yano K. Nitrogen delivery to maize via mycorrhizal hyphae depends on the form of N supplied plant. Cell Environ, 2005, 28: $1247-1254$

56 Chalot M, Blaudez D, Brun A. Ammonia: a candidate for nitrogen transfer at the mycorrhizal interface. Trends Plant Sci, 2006, 11: 263-266

57 Guether M, Neuhäuser B, Balestrini R, et al. A mycorrhizal-specific ammonium transporter from lotus japonicus acquires nitrogen released by arbuscular mycorrhizal fungi. Plant Physiol, 2009, 150: 73-83

58 Kobae Y, Tamura Y, Takai S, et al. Localized expression of arbuscular mycorrhiza-inducible ammonium transporters in soybean. Plant Cell Physiol, 2010, 51: 1411-1415

59 Ruzicka D R, Hausmann N T, Barrios-Masias F H, et al. Transcriptomic and metabolic responses of mycorrhizal roots to nitrogen patches under field conditions. Plant Soil, 2011, 23: 1-18

60 Bago B, Pfeffer P E, Douds D D, et al. Carbon metabolism in spores of the arbuscular mycorrhizal fungus Glomus intraradices as revealed by nuclear magnetic resonance spectroscopy. Plant Physiol, 1999, 121: 263-271

61 Gachomo E, Allen J W, Pfeffer P E, et al. Germinating spores of Glomus intraradices can use internal and exogenous nitrogen sources for de novo biosynthesis of amino acids. New Phytol, 2009, 184: 399-411

62 Jin H R, Jiang D H, Zhang P H. Effect of carbon and nitrogen availability on the metabolism of amino acids in the germinating spores of arbuscular mycorrhizal fungi. Pedosphere. 2011, 21: 432-442

63 Lammers P J, Jun J, Abubaker J, et al. The glyoxylate cycle in an arbuscular mycorrhizal fungus. Carbon flux and gene expression. Plant Physiol, 2001, 127: 1287-1298

64 Yao Q, Ohtomo R, Saito M. Influence of nitrogen and phosphorus on polyphosphate accumulation in Gigaspora margarita during spore germination. Plant Soil, 2010, 330: 303-311

65 Fortin J A, Bécard G, Declerck S, et al. Arbuscular mycorrhiza on root-organ cultures. Can J Bot, 2002, 80: 1-20

66 Azcón R, Rodríguez R, Amora-Lazcano E, et al. Uptake and metabolism of nitrate in mycorrhizal plants as affected by water availability and N concentration in soil. Eur J Soil Sci, 2008, 59: 131-138

67 Subramanian K S, Charest C. Acquisition of N by external hyphae of an arbuscular mycorrhizal fungus and its impact on physiological responses in maize under drought-stressed and well-watered conditions. Mycorrhiza, 1999, 9: 69-75

68 Veresoglou S D, Chen B, Rillig M C. Arbuscular mycorrhiza and soil nitrogen cycling. Soil Biol Biochem, 2012, 46: 53-62

Open Access This article is distributed under the terms of the Creative Commons Attribution License which permits any use, distribution, and reproduction in any medium, provided the original author(s) and source are credited. 